\title{
A Política Externa da Alemanha após a reunificação
}

\author{
FRANK R. PFETSCH*
}

Após a reunificação, quando a Alemanha passou a ter um aumento em seu potencial econômico, e também político, em decorrência da retirada das forças militares das quatro potências vencedoras, e após a dissolução do bloco controlado pela União Soviética, que diminuiu consideravelmente as ameaças oriundas do Leste, apresentam-se para a República Federal da Alemanha novas questões e prioridades.

Na condição de ator do cenário internacional, a Alemanha depara-se com cinco diferentes linhas de ação, que variam conforme ela atue como Estado isolado ou como Parte de uma concepção comunitária. A escala abrange os seguintes níveis: atuação como entidade nacional autônoma; atuação com base no apoio da União Européia (EU) ou de outros Estados; atuação com base na seleção de compromissos; atuação coordenada e harmonizada; e opção por uma atuação coletiva no âmbito da Comunidade Européia (CE) ou da União Européia(EU).

\section{Novas alternativas: condições básicas nacionais modificadas após a reunificação}

Estruturas modificadas, novas potencialidades e nova configuração do cenário internacional implicam novas opções de atuação. Que modificações marcam particularmente o campo de atuação da Alemanha reunificada?

A reunificação implicou sobretudo a seguinte modificação geopolítica: da posição marginal que ocupou durante o período da Guerra Fria a Alemanha

Rev. Bras. Polít. Int. 40 (1): 178-192 [1997].

* Professor de História das Relações Internacionais da Universidade de Heidelberg. Tradução do original alemão de Silas Leite da Silva. 
recobrou sua posição central tradicional na Europa, com uma importante diferença com relação a períodos anteriores: a de que os sistemas de integração e de aliança ocidentais continuam a ser determinantes. AAlemanha tornou-se uma potência média na Europa Centro-Ocidental. Ela está hoje mais a Ocidente que a Alemanha de Bismarck.

As dimensões potenciais alemãs também foram alteradas: a reunificação aumentou o potencial econômico em $10 \%$, a população aumentou $20 \%$ e o território teve um acréscimo de 30\%. Esses fatores, entretanto, não possibilitam à Alemanha tornar-se uma superpotência. Nos três campos do poder-militar, econômico, político - a Alemanha aumentou consideravelmente suas potencialidades, mas continua, porém, em um nível intermediário. Em termos militares, permanece a renúncia às armas atômicas, biológicas e químicas, a limitação do contingente das Forças Armadas e a ausência de um assento permanente no Conselho de Segurança da ONU. No campo econômico, a aplicação dos recursos públicos destinados ao programa de desenvolvimento concentrar-se-á nos novos Landers incorporados a partir da reunificação, e os recursos financeiros destinados à Rússia, cuja alocação foi estabelecida por Acordo, ocuparão as finanças e comprometerão os recursos. O aperfeiçoamento do mercado interno e o esforço em prol da integração econômica e monetária da União Européia constituem possibilidades cuja consecução é das mais importantes para o desenvolvimento econômico e a Alemanha continuará a privilegiá-las na formulação de seus objetivos e em seu processo decisório. Em termos políticos, o modelo de democracia liberal-social não se mostra tão promissor quanto o conceito de sociedade civil existente na Alemanha antes da reunificação. Tal fato relativiza significativamente o potencial de desenvolvimento nessa área.

Não obstante, a reunificação ampliou o campo de atuação da Política Externa da nova Alemanha, a qual passará a apresentar o mesmo grau de importância em relação à política interna e de integração que o observável nos casos da Política Externa da França e do Reino Unido. A Alemanha se comportou como agente relativamente autônomo e atuante, por exemplo, com relação ao conflito que resultou no desmembramento da Iugoslávia, e aumentou sua participação nas atuações da ONU. Da mesma forma, sempre apoiou a integração européia por meio de novas iniciativas, embora as pesquisas de opinião pública demonstrem maior ceticismo com relação a Bruxelas, isto é, a Alemanha adquiriu maior influência e aproximou-se de outros Estados europeus de poder médio como ator nacional e coletivo. 


\section{Novas tarefas da Política Externa alemã e análise de linhas de ação}

Segundo as possibilidades de ação geopolítica, podem-se consubstanciar as seguintes linhas de ação e as opções delas resultantes:

\section{1) A Política para a Europa Oriental (Ostpolitik)}

A Europa Oriental deve ser apontada em primeiro lugar na agenda, uma vez queé dessa região que surgirão as maiores imponderabilidades e inseguranças, que seriam percebidas como ameaças. Nesse contexto, a Alemanha, em razão de seu potencial econômico e interesses estratégicos a longo prazo, deverá despontar como agente autônomo.

Estar voltada para a Europa Oriental significa apoiar a transição da ditadura socialista para estruturas politicamente livres, para o liberalismo econômico e a reestruturação da região da Europa Centro-Oriental. Em consonância com esses objetivos, o Governo alemão deu continuidade à política estabelecida nos Acordos bilaterais firmados com todos os Estados do antigo Pacto de Varsóvia. Todos esses acordos referem-se a princípios do Direito Internacional tal como estão consubstanciados na Carta das Nações Unidas, no Acordo Final de Helsinki, na Carta de Paris e em outros documentos da Conferência sobre Segurança e Cooperação na Europa - e implicam conseqüências pré-estabelecidas. Entre essas encontram-se a consecução da paz, a ausência de violência, a observância dos direitos humanos, a igualdade de soberania, o emprego de meios pacíficos para a solução de controvérsias, a consecução do Estado de direito, a democracia, o direito de livre manifestação, bem como a manutenção do meio ambiente natural. Em termos cronológicos, os objetivos prioritários dos acordos com a Europa Oriental firmados no início da década de setenta resultaram, no período 1990-92, na sucessão de cinco acordos com a União Soviética e, respectivamente, Rússia; dois com a Polônia e um com a Bulgária, Hungria, Tchecoslováquia e Romênia. Outros Estados membros da Comunidade Européia, bem como a própria CE, concluíram acordos semelhantes com Estados da Europa Oriental. A maioria desses acordos contempla promessas de apoio para o ingresso na UE.

A Ostpolitik permanecerá, portanto, importante, ou mesmo tornar-seá ainda mais importante, em razão da persistência da incerteza com relação à evolução dos acontecimentos na política interna da Rússia, bem como nos 
demais Estados da CEI, e porque novas estruturas precisam ainda se desenvolver. Há quatro cenários possíveis para essa evolução: primeiro, a Rússia torna-se uma ditadura nacionalista e retoma a antiga política imperial, procurando, desta forma, exercer influência sobre os países vizinhos; segundo, a Rússia assume a proteção das minorias russas nas ex-repúblicas da União Soviética (Doutrina Kosyrev) e passa, conseqëntemente, a desenvolver uma inevitável atuação regional dominante; terceiro, regiões com parentesco cultural desenvolvem novos laços entre si, como no caso dos Estados da Europa Central, do mar Báltico e da Ásia Central; e, finalmente, quarto, resultam conseqüências imprevistas para a região vizinha: dos Estados da Ásia Central para o Sul (Turquia, Irã, Afeganistão); dos Estados bálticos para Noroeste (Escandinávia, Europa Ocidental); e dos Estados da Europa Central para o Ocidente (EU, OTAN, etc... $)^{1}$. O nível de risco para a Europa Ocidental é, principalmente sob o primeiro cenário, grande, pois nessa hipótese colidem os interesses da Rússia e da Europa Ocidental. O segundo e o terceiro cenário atenuam a possibilidade de conflito entre os Estados da Europa Central e a Rússia. O quarto cenário, de conseqüências imprevisíveis, implicas forçosamente a existência de conflitos, por um lado, entre a Rússia e a Europa Oriental e, por outro lado, entre a Rússia e os países muçulmanos limítrofes.

Em termos econômicos, os mercados da Europa Oriental poderão retomar sua importância a médio ou longo prazo. A curto prazo, entretanto, as perspectivas desses mercados reprimidos não se apresentam como promissoras. As exportações em direção aos países que compunham o COMECON diminuíram consideravelmente a partir de 1990, de modo mais acentuado que as importações, em decorrência de dificuldades de pagamento. Os recursos cuja transferência da Alemanha para a Rússia estava prevista nos acordos destinamse sobretudo ao consumo e não a investimentos, de tal forma que não se pode esperar uma ativação econômica durante o período de reconstrução. Ainda assim, a participação do comércio com a Europa Oriental na balança comercial alemã continua a ser maior que a do comércio com os Estados Unidos.

Essa orientação geopolítica, que objetiva a organização, juntamente com a Rússia, da Europa Oriental, constitui a primeira opção ${ }^{2}$ para a Política Externa alemã; novas relações entre os antigos superpoderes e o eixo Bonn/ Berlim-Moscou levariam a uma delimitação da área de influência compreendida ao longo da linha Finlândia-Países Bálticos-Polônia-Eslováquia-HungriaRomênia-Bulgária. 


\section{2) Política para a Europa Ociental}

Na Europa Ocidental da União Européia (UE) deverá ocorrer o aprofundamento, a ampliação, e democratização e a concretização do Tratado de Maastricht, isto é, a admissão de outros membros implicará a necessária reestruturação dos órgãos políticos da União Européia. A política européia da Alemanha, que visa aprofundar e ampliar a Comunidade Européia nos anos 90, tem sido implementada com as negociações para a consecução da união econômica e monetária com os Governos da CE/EU e objetiva a evolução de um federalismo para a União Européia.

OTratado de Maastricht, de dezembro de 1991, foi fortemente combatido em alguns países. Após o voto popular negativo do referendo dinamarquês, não estava claro que o plebiscito na França resultaria em voto positivo, e a votação na câmara baixa britânica realizou-se com atraso e só teve resultado favorável por ter ocorrido quase ao mesmo tempo que a votação dinamarquesa que aprovou, em segundo turno, o Tratado em maio de 1993. O resultado positivo do referendo na Irlanda repetiu-se nos parlamentos dos demais países membros da CE: Espanha, Portugal, Alemanha, Países Baixos, Grécia, Bélgica, Luxemburgo e Itália. A continuidade desse processo suscita um dilema, que consiste na discrepância entre centralização e democratização (Scharpf: 1992, p. 14), ou seja, entre efetividade (capacidade de negociação) e legitimidade (aceitação). Os Governos alemães optaram tanto pela intensificação da integração quanto por uma ampliação, que não deverá excluir os Estados da Europa Oriental. O modelo ideal para a Europa será contemplado em uma união européia federativa e não deverá resultar em fórmulas intergovernamentais ou supranacionais; isto é, a configuração atual da União Européia pressupõe a ampliação das estruturas federalistas e democráticas. OTribunal Constitucional Federal alemão criou, em sua decisão sobre o Tratado de Maastricht, um neologismo com o conceito de "união de Estados”, cuja configuração situa-se entre os conceitos de “união de Estados” (Staatenbund) e de “Estado federal”(Bundesstaat). A eleição européia de 12 de junho de 1994 ratificou de forma inequívoca o processo de integração da política européia do Governo alemão, embora tenha, contudo, evidenciado igualmente a tendência, em diversos países, de retomada do nacionalismo. No âmbito da política de segurança, a brigada teuto-francesa e o "Eurocorps" significaram o início do processo de europeização e o fortalecimento da União da Europa Ocidental como organização responsável pela segurança européia.

A Alemanha atuou em sua política européia de forma autônoma (reconhecimento das ex-Repúblicas da Iugoslávia), com base na seleção de apoios 
(Eurocorps), e no âmbito comunitário (Comunidade Européia e política relativa à União Européia).

O aprofundamento do debate permite visualizar uma segunda opção para a Política Externa alemã, consubstanciada na Europa Carolíngea (Ash), tendo como países centrais a Alemanha, a França e o Benelux, e como objetivo os “Estados Unidos da Europa”. Esse conceito propicia àAlemanhaa possibilidade de não ser colocada em uma posição intermediária.

A ampliação do debate permitiu ainda visualizar uma terceira opção para a Política Externa alemã, que consiste em uma Europa Ocidental ampliada a partir do ingresso de países escandinavos e da Europa Oriental. Ver-se-á que, no presente momento, ela se apresenta como a melhor opção para os interesses econômicos, políticos e de segurança da Alemanha reunificada.

\section{3) Parceria Transatlântica}

Deve-se buscar um entendimento com os Estados Unidos com relação à futura estrutura do sistema de segurança comum, incluindo a Europa Oriental. A área de atuação da política de segurança requer novos conceitos básicos para a solução de crises como as ocorridas na Europa Oriental (ex-Repúblicas soviéticas e Iugoslávia). Em termos econômicos, obter-se-ía com a cimeira do G-7 um instrumento de regulamentação entre os Estados industrializados ocidentais mais importantes e o trilateralismo América do Norte (NAFTA) Europa (UE) - Ásia Oriental (Japão), estabelecendo, com todos os seus interesses antagônicos, as bases futuras para a atuação no campo econômico. Isso pressupõe, sobretudo para o Estado industrial e comercial da Alemanha um papel de importância maior que para os demais membros da UE, os quais apresentam maior nível de entrelaçamento econômico com a UE. Em 1990, mais de $80 \%$ do comércio exterior da Alemanha foi efetuado com Estados industrializados ocidentais; a participação dos doze Estados da UE atingiu cerca de $50 \%$, isto é, $30 \%$ do comércio exterior é realizado com países industrializados ocidentais não-membros da UE. Os interesses econômicos também apontam para fora do mercado europeu e encontram sua expressão no apoio à liberalização do comércio mundial. Nesse caso, convergem os interesses norte-americanos e alemães.

A nova orientação do relacionamento euro-norte-americano tornou-se necessária não apenas em decorrência da dissolução do império soviético, mas também em razão do deslocamento do peso entre ambos os pilares transatlânticos. A administração Bush considerou a OTAN o mais importante fator de união do 
mundo ocidental, em relação à qual a União da Europa Ocidental ou a Conferência sobre Segurança e Cooperação na Europa devem-se situar em posição secundária. Os europeus reivindicam mais igualdade de direitos no âmbito da aliança da OTAN, Bush aquiesceu, oferecendo em contrapartida o conceito de "burden sharing"; Reagan já havia-se referido, com relação à Alemanha, ao conceito de "partners in leadership", e a administração Clinton oferecera um "special relationship”. A “parceria para a paz”, bem como a oferta da OTAN, inspirada por Clinton, ao Leste europeu procurou contemplar igualmente a Rússia e os Estados da Europa Central.

A questão mais importante que se coloca para a Política Externa é, tendo em vista as divergências econômicas, a consecução, por meio da "concordância” (Schwarz:1980) e da "harmonia” (Morgan:1984), de uma política determinada ; em termos gerais, a atuação pode ser denominada como coordenada. O referido processo de reunificação pode ser apontado como prova inequívoca dessa atuação

O alinhamento com os Estados Unidos proporcionaria à Alemanha uma quarta opção, que consiste no desempenho de um papel mundial sobretudo no âmbito do trilateralismo econômico e seria apoiada principalmente pelos membros da OTAN e pelos partidários da globalização. A oferta de Clinton de um “special relationship” entre os Estados Unidos e a Alemanha decorre da concepção de um intergovernamentalismo europeu tendo a Alemanha como líder.

\section{4) A participação alemã no âmbito da $O N U$}

A participação dos alemães na ONU ampliou-se nos anos oitenta. Unidades policiais alemãs a serviço da ONU fiscalizaram a realização de eleições na Namíbia e no Camboja; navios alemães participaram do controle que visava garantir a observância do embargo decretado pela ONU na costa adriática da Iugoslávia; e vôos de suprimento a zonas de guerra na BósniaHerzegovina foram realizados no contexto de missões da ONU. Durante a segunda Guerra do Golfo, unidades da Aeronáutica alemã já haviam estacionado em território turco. Unidades de auxílio humanitário - hospitais militares, instalações destinadas a irrigação e abastecimento de água - foram igualmente postos a serviço na Somália. Essas medidas destinaram-se, até então, mais à manutenção que à consecução da paz.

A discussão sobre a política interna alemã gira em torno da participação de capacetes azuis no âmbito da ONU. AConstituição tem sido sempre utilizada como argumento em favor e contra um maior engajamento em ações de caráter 
militar. O Tribunal Constitucional Federal declarou, em sua decisão de julho de 1994, que a colocação de unidades do Exército alemão a serviço de missões realizadas no âmbito da ONU, após a aprovação do Parlamento, é compatível com a Constituição. A pretensão alemã de obter um assento permanente no Conselho de Segurança da ONU torna necessária a reformulação ampla deste grupo decisório de tal modo que se harmonize com as novas realidades características do período subseqüente ao final da Guerra Fria e responda adequadamente às novas questões fundamentais na Europa, no Terceiro Mundo e no Pacífico (Japão).

Até o momento, a política do Governo alemão com relação à ONU apresentou características de estreita coordenação, tendo demonstrado até mesmo uma atuação comunitária integrada. As disposições da Constituição seriam utilizadas, devida ou indevidamente, pelos adversários de um engajamento mais significativo como argumento em defesa de uma atuação passiva.

Qual das opiniões referidas deveria prevalecer? A resposta a essa questão deve ser formulada em dois estágios, ou seja, uma vez por meio do resumo encontrado na literatura das orientações evidentes, e, por outro lado, pela fundamentação da opção pela ampliação para o Leste.

\section{A discussão a respeito da orientação para uma nova Política Externa alemã}

De que forma são percebidas as mudanças internacionais, regionais e nacionais pela literatura acadêmica alemã, e como serão elas interpretadas e julgadas? Essas mudanças internas e externas têm sido analisadas por novas publicações com base em parte no contexto visível do imediato pós-guerra. A discussão ocorre em torno de temas estratégicos, como o engajamento militar no âmbito da OTAN e da ONU, mas também de temas relativos à interdependência, pouco discutidos até o momento, como, por exemplo, a ligação com o Ocidente e a manutenção do caráter nacional em uma Europa integrada, ou sobre geopolítica. O fim da Guerra Fria e a reunificação alemã ampliaram o espectro de opiniões e tornaram discutíveis opiniões aceitas por longo período. Um livro com o título Ligação com o Ocidente: Oportunidades e Riscos para a Alemanha, que propõe a relativização da política de integração com o Ocidente, idéia que ainda não havia sido apresentada nos anos oitenta, permite visualizar efetivamente uma tendência de desengajamento em relação ao Ocidente. Para a geração nascida na Alemanha, Wehler refere-se de forma polêmica ao "pensamento brilhante” e aos "gurus apresentadores de miragens" 
da “nova Direita agressiva” (U. Wehler em Frankfurter Allgemeine Zeitung, de 6/5/1994).

Pode-se considerar três posições ideológicas com relação à orientação a ser seguida pela Política Externa alemã após a reunificação: uma nacionalconservadora de direita, uma de esquerda e uma de centro-liberal. No espectro direito do ponto-de-vista ideológico será acentuado o papel autônomo da Alemanha e será defendido um maior engajamento na política internacional, como se pode verificar nas revistas Junge Freiheit, Mut e Criticon; alguns autores buscarão o instrumento para a solução dos problemas existentes no Estado nacional que se tornou anacrônico; prometer-se-á o "Primado da Nação" (Weissmann), a "posição intermediária histórica” será salientada, bem como a advertência contra a "utopia de uma integração total com o Ocidente” (Zitelmann). Entretanto, pode-se perceber claramente na literatura acadêmica tradicional uma reserva com relação a um caminho autônomo, caracterizado pelo afastamento dos Estados Unidos e pelo reconhecimento do anti-americanismo; ela reclama, contudo, a redução do peso dos Estados Unidos e o crescente engajamento da Alemanha. O crescente poderio não deveria, porém, ocasionar uma "nova megalomania” (Baring:1988) ou um "esquecimento pastoral do poder" (Schwarz:1985) por parte de um pacifismo alemão, mas ser devidamente considerado e utilizado. Os procedimentos caóticos na periferia e a configuração instável, perigosa e insatisfatória do poder mundial requerem um engajamento nacional mais efetivo e uma consciência dos instrumentos de uma "política de poder responsável” (Schwarz:1995). Nesse contexto, o emprego de instrumentos militares para pôr fim e impedir conflitos regionais não deve constituir um tabu. Trata-se, para a Alemanha, segundo Schwarz, em primeiro lugar, da manutenção da democracia liberal, e, em segundo lugar, da auto-afirmação das Repúblicas livres, e, finalmente, da “co-responsabilidade pelo ordenamento global”.

Há duas correntes que não devem ser seguidas: uma que defende o aumento inconseqüente do poder sob o pretexto de defender os legítimos interesses de segurança, e outra que advoga ceder à pressão de um público ávido de paz que esquece o poder. Requer-se uma "política de poder eticamente responsável” (Hacke:1988), não a política irresponsável da violência ou uma política caracterizada por uma ética baseada nos postulados do Sermão da Montanha. Alguns autores propõem pensar além do Tratado de Maastricht e aceitar o “estatismo nacional” (Mayer).

No espectro ideológico da esquerda ver-se-á sobretudo o perigo de uma Alemanha "hegemônica na Europa”, que exercerá pressão sobre a construção e democratização das estruturas européias. Ao avaliar uma estrutura instável, 
as posições da esquerda vão ao encontro daquelas da direita, com a diferença de que o perigo de turbulências decorreria dos mercados internacionais (Narr, Deppe Hufschmid em C. Thomas et al.: 1993). Trata-se, portanto, de intensificar a institucionalização da regulamentação da política econômica e monetária entre a América do Norte, a Ásia Oriental e a Europa Ocidental, de forma a amortecer as instabilidades estruturais do desenvolvimento capitalista. Foram formuladas objeções à Teoria do Estado Mercantilista dos liberais: as contradições estruturais da economia capitalista provocaram crises e predisposição para instabilidades, cujas conseqüências para as metrópoles e deformações em áreas periféricas do mundo foram negligenciadas. Pode-se encontrar nessas obras uma defesa da manutenção da estrutura política da velha Alemanha, incluindo a proposta de superar os grandes paradoxos no interior e a diferença Norte-Sul no exterior.

A nova Alemanha deveria permanecer com seu discreto papel militar e abster-se de demonstrar qualquer presença nos cenários bélicos internacionais. Decorreu dos movimentos pacifistas a idéia de uma Alemanha desmilitarizada, que se retire da aliança da OTAN (Albrecht:1992); serão condenadas as noções de "estilo clássico de potência”, "poder europeu hegemônico” ou “política de poder militar”.

Um centro liberal amplo, ao qual pertence a maioria dos cientistas políticos alemães, defende igualmente a continuidade da evolução da Política Externa da Alemanha, e enfatiza a crescente interdependência, pretendendo atribuir maior peso à Europa unida no contexto político mundial. A Teoria do Estado Mercantilista, que Rosecrance colocou em debate, será considerada; a República Federal da Alemanha deveria continuar sendo um Estado mercantil civil, ou seja, um "Estado mercantil democrático cooperativo internacional" (Rittberger:1990). Nesse contexto, omitir-se-á que a Alemanha jamais foi um Estado unicamente mercantil, como Cingapura ou Hong-Kong, mas que possui a base para uma sociedade industrial. Na perspectiva liberal, o perigo de instabilidade na periferia decorrerá de relações de dependência superáveis (Kohler - Koch: 1989), e as ações de um Estado isolado serão harmonizadas com as de outros Estados. A nova Alemanha não deve fixar-se nem esquecer o poder, e, em nenhuma hipótese, significar o "nascimento de um novo superpoder alemão". A avaliação preliminar do peso da nova Alemanha resultará antes no desempenho de um papel discreto, de tal forma que a participação da Alemanha na estrutura de integração ocidental evite o isolamento nacionalista; que ela não seja uma “économie dominante”, mas, ao contrário, limite o próprio peso com sua integração na União Européia. Os interesses da Política Externa alemã situariamse, de acordo com Bredow e Jäger (1993), na prevenção da guerra, no ordenamento do comércio mundial livre, na estabilidade da integração européia, 
na possibilidade departicipação dos atores sociais, no estabelecimento deestruturas parlamentares democráticas, na diminuição do desequilíbrio entre os Estados industrializados e os países em desenvolvimento, no desaparecimento de falsas projeções sobre a imagem daAlemanha, bem como na política de integração com o Ocidente. A integração européia, a cooperação trilateral e a coordenação européia como um todo são, portanto, prioritárias, da mesma forma que a intensificação das relações bilaterais.

Em resumo, surgem consensos ediferenças. Em primeiro lugar, surpreende a unanimidade com relação à boa qualidade da Política Externa da velha Alemanha, cujas posições básicas devem ser aceitas - ao invés de serem modificadas - e continuar a ser desenvolvidas. Essa nostalgia com relação à velha Alemanha surpreende particularmente também em decorrência de seu desenvolvimento, que estava e está marcado por duas correntes opostas; desta forma, omitiu-se, por exemplo, a Resolução do Congresso Nacional da Aliança 90/ Partido Verde no final de fevereiro de 1994 sobre a renúncia a todo e qualquer armamento e a eliminação das Forças Armadas na Alemanha, que revigorou o antigo movimento pacifista.

A coincidência de posições entre a direita e a esquerda, por outro lado, não é tão surpreendente, pois ela não ocorreu tão raramente ao longo da História. Diferente é, porém, a percepção do perigo de instabilidades no mundo exterior, o que leva a diferentes avaliações com relação a seu controle. A direita vê uma solução efetiva no modelo estatal nacional da política de poder, enquanto a esquerda e os liberais querem ver a estrutura internacional ampliada emodificada.

Nenhuma das três posições apresentadas deseja, no entanto - com exceção de grupos minoritários do Partido Verde e do Partido do Socialismo Democrático - uma mudança radical na posição básica da velha Alemanha, ao menos com relação à aliança ocidental e ao sistema de integração.

Trata-se unicamente de modificações erelativizações, estas mais graves, que já começam a ser visíveis.

\section{Defesa de um novo papel de ligação}

As quatro opções igualmente propostas por Timothy Ash, a opção pela Rússia, a opção carolíngea, a opção pela Europa ampliada ou a opção pelo desempenho de um papel mundial, foram e são consideradas concomitantemente corretas; o “Genscherismo”, definido principalmente pelo “tanto-quanto”, e não pelo “isto ou aquilo”, será continuado sem o ex-Chanceler alemão, ou seja, terá a 
mesma importância do "special relationship" dos Membros da OTAN com os E.U.A., ou dos gaullistas com a França, ou do aprofundamento da União Européia - tendo Bonn-Paris como centro, ou de sua ampliação para os Estados da Europa Oriental, ou ainda do aprofundamento das relações com os Estados da Europa Oriental bem como com a Rússia.

Os interesses e as necessidades do comércio caracterizam-se por determinadas prioridades a serem estabelecidas e, neste contexto, a Europa Oriental situa-se em primeiro plano nos anos noventa.

A determinação da posição da Alemanha como um Estado industrial e comercial no centro do continente europeu pode ser vista como uma função de ligação com um sólido atrelamento na aliança ocidental, como força impulsionadora, por um lado, do aprofundamento e ampliação e, por outro lado, de abertura para o Leste e para a renovação econômica e política dos exEstados socialistas. Essa função de ligação é tudo menos uma variação nacionalista do conceito de ligação, do neutralismo, de um Centro independente ou mesmo de um caminho autônomo; trata-se antes de um conceito de defesa dos próprios interesses econômicos, políticos e de segurança, que ultrapassam amplamente os interesses militares (Pfetsch:1993), a superação do abismo social entre o Leste e o Oeste e a superação da divisão ideológica prevalecente no período da Guerra Fria. A tarefa histórica poderia-se constituir em levar as virtudes da velha Alemanha para o Leste.

Enquanto a política para o Ocidente foi consubstanciada sobretudo na ligação com os demais Estados da União Européia, a política para a Europa Oriental tem-se caracterizado por uma atuação autônoma com vistas à consecução de uma política coordenada. A ação mais independente em relação à Europa Oriental e ao mundo em desenvolvimento não significa qualquer distanciamento da aliança Ocidental; o Reino Unido e a França também apresentam, juntamente com seu engajamento na Europa, um perfil de ator nacional autônomo. A política de integração e a de Estado individual não são excludentes, como tem demonstrado a experiência histórica desde o início do processo de integração europeu (Pfetsch: 1994,p. 120-137).

No plano político, deve-se retomar a discussão e a negociação da coordenação da Política Exterior bilateral e multilateral.A discussão a respeito do meio a ser empregado éinútil se aplicada a diferente posições políticas. Apolítica de integração ocidental requer instrumentos empregados nas estratégias clássicas de negociação bilateral e multilateral e corresponderá ao empenho pelo princípio da interdependência; para a superação dos conflitos - principalmente das disputas bélicas - também é necessário, dependendo das circunstâncias, o emprego de 
recursos militares, que integram o arsenal das avaliações realistas. Ambas as avaliações são válidas e complementam-se no tocante à realização de diferentes tarefas.

O objetivo da Política Externa alemã era - como estabeleceu a Carta para a Unidade Alemã de 1970 - "o de atingir e manter um estado de paz na Europa, no qual o povo alemão pudesse recuperar sua unidade na autodeterminação”. Para os próximos anos, o objetivo da Política Externa alemã deveria denominar-se "dedicação a um estado de liberdade na Europa, no qual a Alemanha tem aliados na Europa Ocidental e parceiros na Europa Oriental”.

A escolha desse papel significa, em primeiro lugar, a continuidade de ambos objetivos básicos da Alemanha em sua História, que são a integração com a Europa Ocidental nos anos cinqüenta e a abertura para a Europa Oriental nos anos setenta sob as novas condições surgidas a partir da reunificação nos anos noventa. Desse modo, a relação entre a Política Externa e a política interna permanece válida, isto é, a combinação entre a democracia e a economia social de mercado com a orientação para o Ocidente. A ligação tem - para permanecermos nessa imagem - de um lado um pilar firme e, de outro lado, uma consolidação mais frouxa.

Abril de 1997

\section{Notas}

1 Ver, sobre esse assunto, Klaus SEGBERS: “Die neue Unübersichtlichkeit”, in: Die Gemeinschaft Unabhängiger Staaten (GUS). Stuttgart: 1992, pp. 192-208.

2 Baseamo-nos no artigo de Timothy Ash sobre a questão das opções para a Política Externa alemã.

\section{Bibliografia}

ALBRECHT, Ulrich. "Die Abwicklung der DDR: die 2+4 Verhandlungen”; in: InsiderBericht(WdV). Opladen, 1992.

ASH, Timothy Garton. Germany's Choice. Foreign Affairs, vol. 73, n 4, julho-agosto de 1994.pp.65-81. 
BARING, Arnulf. Unser neuer Grössenwahn: Deutschland zwischen Ost und West, (DVA). Stuttgart, 1988.

BAUMAN, Zygmunt. ARevolution in the Theory of Revolutions? IPSR, vol. 15, $\mathrm{n}^{\circ}$ 1, 1994. BREDOW, Wilfried von e JÄGER, Thomas. Neue deutsche Aussenpolitik. Nationale Interessen in internationalen Beziehungen (Leske \& Budrich). Opladen, 1993.

HACKE, Christian. Weltmacht wider Willen. Die Aussenpolitik der Bundesrepublik Deutschland (Klett-Cotta). Stuttgart, 1988.

KOHLER-KOCH, Beate. Regime in den Internationalen Beziehungen (Nomos). BadenBaden, 1989.

MORGAN, Roger. The US and West Germany 1945-1979. London, 1974. Washington und Bonn. Deutsch-amerikanische Beziehungen (Piper). München, 1974.

PFETSCH, Frank R. Die Aussenpolitik der Bundesrepublik1949-1992. Von der Spaltung zur Vereinigung (UTB Fink). München, 1993.

PFETSCH, Frank R. “Tensions in Sovereignty: Foreign Policies of the EC Members Compared”, in: CARLSNAES, Walter e SMITH, Steve. 1994, p. 120 e seguintes.

PFETSCH, Frank R. Sicherheit als Begriff der internationalen Politik. Geographische Zeitschrift, 1993, H. 4, pp. 210-226.

PFETSCH, Frank R. Internationale Politik. (Kohlhammer). Stuttgart, 1994.

RITTBERGER, Volker. Die Bundesrepublik Deutschland - eine Weltmacht? Aus Politik und Zeitgeschichte, pp. 4-5/19, januar, 1990.

ROSECRANCE, Richard. Der neue Handelsstaat. Frankfurt, 1987.

SCHARPF, Fritz W. Europäisches Democratiedefizit und deutscher Föderalismus. Beitrag an die Gemeinsame Verfassungskomission. Berlim, 1992.

SCHWARZ, Hans-Peter. Vom Reich zur Bundesrepublik. (Klett-Cotta). Stuttgart, 1980.

SCHWARZ, Hans-Peter. Die gezähmten Deutschen. Von der Machtbesessenheit zur Machtvergessenheit. (DVA). Stuttgart, 1985.

THOMAS, Caroline e WEINER, Klaus-Peter (orgs.). Aufdem Weg zur Hegemonialmacht? Die deutsche Aussenpolitik nach der Vereinigung (Papyrossa). Köln, 1993.

WEHLER, Hans-Ulrich. Gurus und Irrlichter. Frankfurter Allgemeine Zeitung, n 105, 6. Maio de 1994.

ZITELMANN, R., WEISSMANN, K., GROHEIM, M. (orgs.). Westbindung. Chancen und Risiken für Deutschland (Propyläen). Frankfurt/Berlin, 1993.

\section{Resumo}

Análise das opções abertas à Alemanha no período após a reunificação, enfatizando seu papel internacional, seu protagonismo comunitário e sua função de ponte entre a Europa Ocidental e a Eurásia. 


\section{Abstract}

Analysis of the options opened to the Germany after the reunification, emphasizing the international role of FRG, its euro-protagonism and its bridgebuilding function between Western Europe and Eurasia.

Palavras chaves: Alemanha. Política externa. Reunificação.

Key-words: Germany. Foreign policy. Reunification. 